\title{
9 Lessons from Lomani Gau Project, Fiji: A Local Community's Response to Climate Change
}

\subsection{Introduction}

Life in the Pacific Islands is being transformed by climate change: higher temperatures are causing coral bleaching and will affect crops and biodiversity; rising seas are consuming the coastal areas and causing salt water intrusion that is affecting freshwater supplies; carbon dioxide emitted by fossil fuel combustion is being absorbed by the ocean, resulting in changing $\mathrm{pH}$ levels leading to ocean acidification; and more frequent and severe storms and tropical cyclones will exacerbate floods and loss of human lives and property. Climate change is altering ecosystems and affecting how Pacific Islanders live in their small island developing states-already burdened by rapidly increasing populations; limited land area; restricted natural resources to accommodate people's development aspirations; limited finance and scarce and unskilled labour. With such wide-ranging impacts on people's lives, climate change is regarded as the greatest challenge to life in the Pacific Islands in years ahead. This makes the effort of Pacific Islanders to live with climate change remarkable. While climate change adaptation is everybody's responsibility and Pacific Island Governments are taking action at national and international levels, the focus in this paper will be on how local communities that are dependent on their land and marine resources are taking action to protect their sources of livelihood and adapt to the new reality ravaged by climate change.

Local Fijian communities heavily depend on their island environment that is dominated by the sea and marine resources. These people are at the forefront of attempts to live with climate change, which is expected to have devastating impacts that may mean relocation and the alteration of all their rights. Although indigenous Fijians have ownership rights over their environmental resources whose uses are regulated under customary arrangements and practices, Fijians today have to ensure that their environmental resources provide for them as well as succeeding generations in a time when customary arrangements may no longer be effective and appropriate. Already, many of the time-tested customary arrangements have been altered owing to the transition to a cash-based economic system and other aspects of globalisation now witnessed in the country. In addition, Fijians have to adapt to changing climatic conditions using both the knowledge and practices of

Joeli Veitayaki, Elisabeth Holland, University of the South Pacific 
their ancestors alongside appropriate contemporary methods spearheaded by their governments and civil society organisations. It is critical that the people quickly realize that their best development option is to ensure that their natural resources continue to provide for them in the future even in the face of climate change, increasing populations and other pressures.

This chapter highlights the effects of climate change in a rural indigenous Fijian community where it is customary to prepare for eventualities while there is still time (vakarau ni se siga toka-prepare while there is still daylight). The paper will examine how the people on Gau Island relate to climate change and how they are dealing with it. The chapter demonstrates how the people have addressed the effects of climate change, and contributed to the climate change discourse in a distinctive way. This is a co-management arrangement where outside partners including the authors worked with the local communities who have customary ownership rights to formulate a resource management approach that is relevant to the local people as well as reflective of the need to adapt to climate change. This approach has allowed the external partners to filter the climate change discourse in terms that are relevant to the people, secure the necessary funding support and work with the local communities to determine an appropriate set of activities to address the effects of climate change.

The partners organised capacity building workshops and meetings at various levels to ensure that the messages are widely known and are used to design local solutions. The involvement of local people was more challenging as it meant redefining some of their established practices and ideas. The Lomani Gau network was the outcome and solution; it provided an association of people committed to improving their living conditions for the long run. The network formulated resource management plans for each village, which were then shared with the local communities and are implemented and monitored.

To be relevant to local communities who were often misrepresented as being free and idle, there was a need to explain climate change in local terms and local solutions to convince them of the urgency for local action. In addition, it was important to maintain the attention and focus of these local communities who often are not committed to long term targets. Consequently, rural development initiatives have to be revised to make them consistent to climate change concerns. Fortunately, the common features shared with sustainable development, integrated management and precautionary principle are not difficult to re-establish in communities where the people have complimentary customary practices. It is rewarding when the people themselves make the connections and explain the influence of climate change locally.

The Lomani Gau initiative shared in this paper demonstrates the work that local communities in Gau have undertaken in engaging climate change, figuring out what it means locally and how it can be accommodated and how it changes "customary" practices, relations, responsibilities and knowledge. To show the 
appropriations that have happened in Gau, the chapter will focus on the setting on the island, the engagement process to convince people of the need to address the issues, the actions that the people have taken to protect their own interests and those of future generations, the challenges relating to other societal changes that have to be addressed and the lessons from climate change adaptation that should be shared to make people better adapt to changing conditions.

\subsection{Gau Island: The Setting}

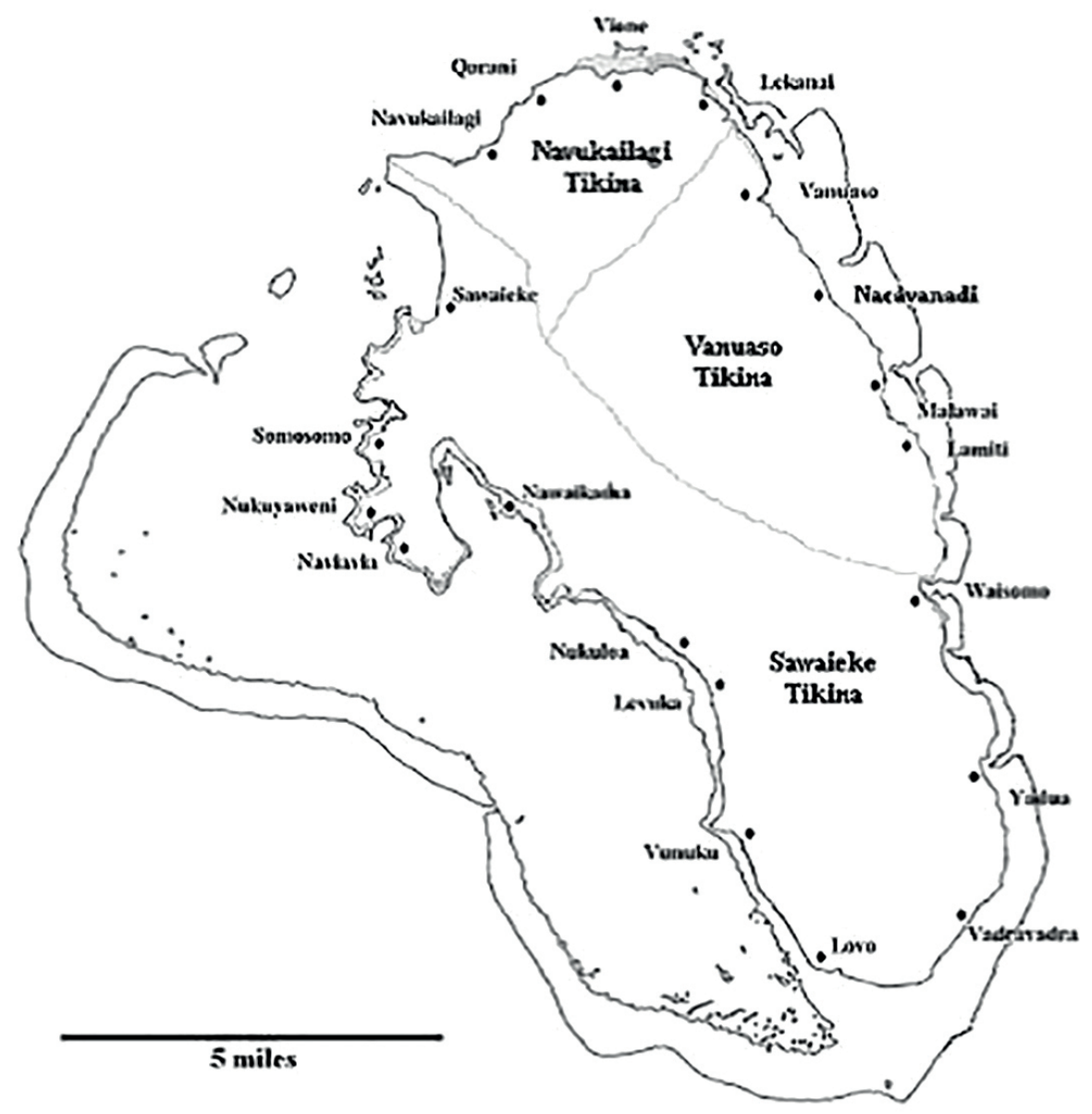

Figure 9.1: Map of the Fiji islands. Courtesy of Joeli Veitayaki and Elisabeth Holland.

Gau Island lies $80 \mathrm{~km}$ east of Fiji's capital Suva. It is the fifth-largest island in Fiji, with an area of $190.1 \mathrm{~km}^{2}$ (Map of Fiji). A rugged mountain range that peaks at around 
$738 \mathrm{~m}$ runs along the interior of the island to which coastal lowlands and river plains connect. The central highlands are covered with old-growth cloud montane forests that are home to the endemic Kacaunigau or Fiji Petrel (Pseudobulweria macgillivrayi), some endemic plants and sites of ancient settlements. The forests have not been logged, providing the people with clean water and air, wild food, building materials, herbal medicine, farming implements, and household goods. The coastal areas, in contrast, have been heavily impacted by human activities and, as we will see, must be rehabilitated if locals are to successfully adapt to climate change.

A barrier reef system encircles Gau providing the people with: varieties of seafood such as finfish, bivalves and echinoderms; sources of income such as fishing, shipping, research, live rock and ornamental fish, shark feeding and whale watching; as well as building materials such as sand and coral rubble mining, coral sale, gravel trading. The coral reef system also protects the $100.3 \mathrm{~km}$ coastline from huge storm waves and surges.

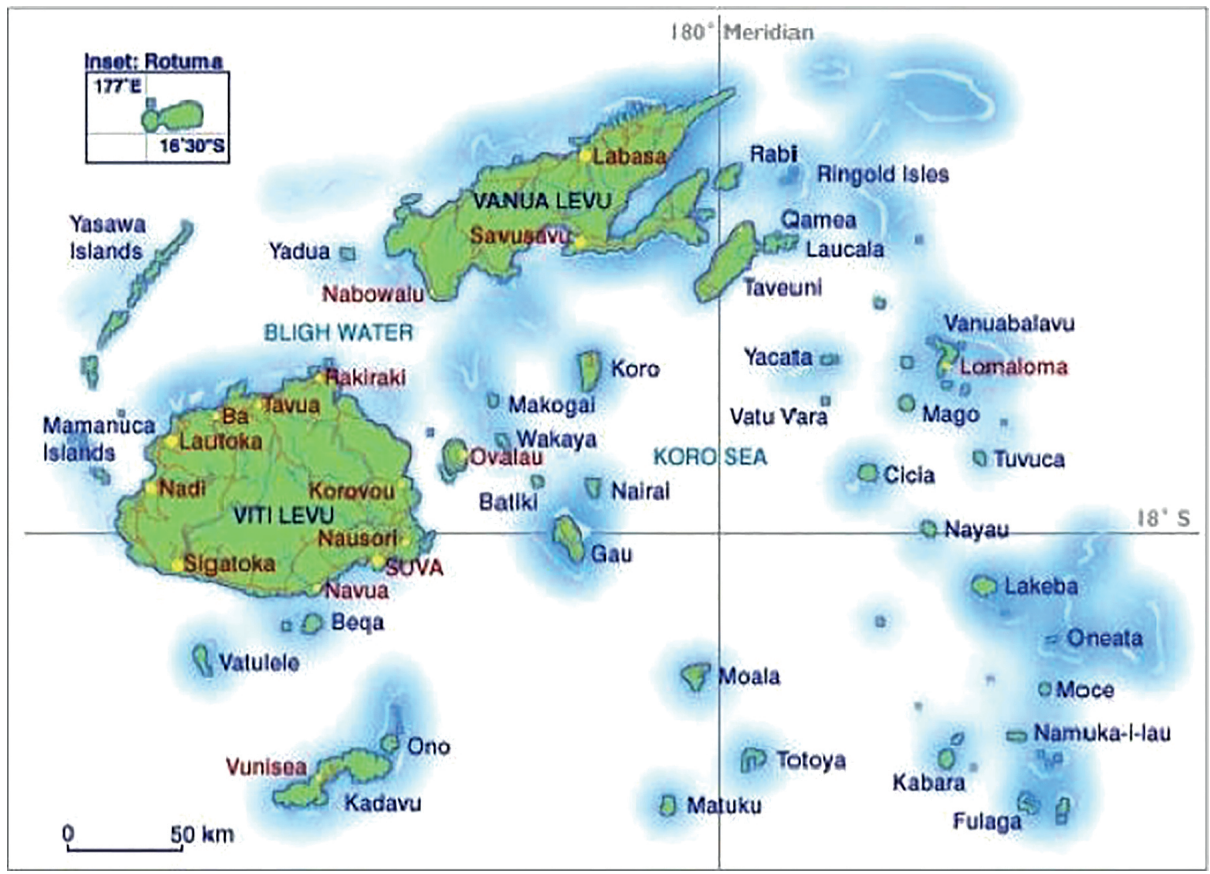

Figure 9.2: Gau island. Illustration courtesy of Joeli Veitayaki and Elisabeth Holland.

Gau Island is divided into three administrative units (tikina) that resemble customary affiliations that reflected pre historic migrations and settlement. The three districts are: Sawaieke, which consists of eight villages of Sawaieke, Somosomo, Nawaikama, Nukuloa, Levuka, Lovu, Vadradara and Yadua and three settlements in Nadrodro, 
Matainaro and Lele; Navukailagi, which has three villages of Navukailagi, Qarani and Vione and a Seven Day Adventist's settlement; and Vanuaso, with five villages of Lekanai, Vanuaso, Nacavanadi, Malawai and Lamiti and two settlements in Wailevu and Baravi (Map of Gau). All the villages are located in coastal lowlands but the villagers have land claims that stretch from the mountains in the interior to the areas beyond the outer slopes of the barrier reefs. Most of the villages in Gau are located on river banks next to hills near that provide convenient evacuation spots from floods, as well as tsunamis.

Gau Island is home to around 3,000 people. Though traditional livelihoods (subsistence farming and fishing) remain crucial, Gau communities are also rapidly modernizing. Increasing populations, expanding farms, increasingly intensive fishing, greater use of fuel-powered transportation and energy generation, increased harvesting of local resources for sale in urban areas, and expanding infrastructure have increased local environmental impacts and undermined valuable ecosystem services. Sustainable development initiatives are therefore a necessity for the continued well-being of Gau Islanders.

While the scientific discourse on climate change is important in understanding humanity's role in its continually worsening state, it has to be filtered and used in a manner that will help convince the people to take action. The engagement process is critical because climate change is a relatively new issue that can easily be misrepresented if the climate science is emphasised when the issue is discussed with local communities. Failure in this delicate phase can wrongly reassure the people, who will dismiss the importance of the issue and their own involvement. In addition, the people will not realise the urgency of addressing the climate change issues now. The demand in developing countries for donors to pay for the adaptation and mitigation, demonstrate the failure in local communities to engage. In fact, the dependence on western science that focuses on emission figures, provided these developing countries false hope that their contribution is negligible and that local communities are not responsible and must only follow the lead by developed countries. The emphasis on climate science also inhibits the influence of other societal challenges such as everincreasing population, poverty and environmental degradation on climate change. Ironically, the developing countries can all contribute to climate change adaptation and mitigation by better addressing these social challenges.

Given that local communities in the Pacific region, such as in Fiji, will be amongst the first and worst climate change victims, Pacific Islands and Territories need to be pragmatic to protect their own interests using all the resources and avenues available to them. Local communities such as those in Gau Island need to look for solutions that are appropriate for them. Not doing anything to address climate change, is not an option. In this case, the Lomani Gau partners from the University of the South Pacific and elsewhere adopted a more practical approach emphasising the impacts of climate change on the environment. The focus on Gau is on the causes and impacts of rapid coastal erosion, pollution and altered coastal habitats that people rely on for 
their sustenance and income. The local communities also emphasised the important threats caused by rapidly increasing population and worsening poverty. These distinct but related issues were more relevant to the local people, who agreed to be prudent with their use and care of environmental resources.

The aims of Lomani Gau are to:

- make Gau Island a model for climate change adaptation in small islands in transition from subsistence to commercial and economically viable rural development.

- conduct participatory learning and action training workshops and meetings to raise climate change awareness and stimulate self-determined climate change adaptation responses.

- formulate and implement Gau Island climate change adaptation and sustainable development guidelines.

- rehabilitate important natural habitats under increasing threat from human activities.

- reduce environmental degradation of natural habitats.

- use science and appropriate technologies to determine sustainable use of island resources.

- build capacity and promote good environmental resource use practices within Gau.

- promote integrated resource management and iterative learning.

- facilitate development of alternative sources of livelihood and income, monitoring and enforcement through regular follow-up and applied research activities.

- publicise the villagers, their flora and fauna, local culture, traditions, and way of life in Gau, and their importance.

- promote project features through publications and the production of visual aids.

With these activities, it is difficult to relate the need for action to the international instruments and national legislation and policy because the majority of the people have little or no knowledge of these. This is why it is sensible to integrate local knowledge and practices to mobilise indigenous, place and community-based initiatives to adapt to climate change because this is the logical thing to do. Moreover, it makes sense for people to take action using customs and traditions they are familiar with rather than rely on conventions and legislations they know little about. Links to climate change scientific predictions and theories are only shared once the people start to work on their adaptive activities.

\subsection{The Engagement Process}

With the need to use appropriate engagement processes in local communities in Fiji, the mobilisation of local people to adapt to climate change adaptation on Gau 
is founded on people's strong relations to nature (Henocque and Denis, 2001) and to each other. The people have customary ownership rights that they need to sustainably utilise for their sake and the interests of their future generations. This relationship is used to ensure the involvement of local people in the adaptation to climate change on Gau. The people are integrating their traditional practices with contemporary arrangements and are using social relations and networks to emphasize commitment, connections, compliance and collaboration.

The Gau communities' response to climate change challenges is packaged under the activities of Lomani Gau ("care for" or "deeply treasure”), which was established in 2005 to spearhead this community-based resource management initiative involving all 16 villages on the island, working towards climate change adaptation in the face of burgeoning climate change and the myriad of other threats to the livelihood base. Lomani Gau was formed to implement, coordinate, lead, monitor and review community-based sustainable rural development on the island. The other intention of Lomani Gau is to strengthen the governance at the Gau Island Council level so that the rural development issues and initiatives are better coordinated.

The initiative emphasises locally deployable solutions that feature contemporary sustainable development methods, as well as traditional practices. The use of people's proven and cost-effective traditional methods reduces the uncertainty with which resource management is associated, and obviates the need for extensive training, as traditional methods are already well-known to the participants.

The most commonly used resource management method in Gau is the $t a b-a$ prohibition of harvest or use of resources, areas, and/or at particular times. This resource stewardship method that is widely practised throughout the Pacific (Williams, 1982) demonstrates the commitment amongst these communities to make the harsh and tough decisions. Under this arrangement, which works better than other contemporary methods because it allows the replenishment of the resource by reducing the fishing effort, compliance is ensured through fear of divine punishment, respect for the authority of chiefs, and commitment to the wellbeing and honour of the group members. This makes costly formal enforcement and monitoring measures unnecessary and ensures that the actions agreed to by the villagers are respected by all.

The Lomani Gau initiative was initially trialled in one of the three tikina on the Island as Mositi Vanauso, named after the kin-based customary marine tenure system that exists. This calculated step to enhance the involvement of all the people that have customary right to the fishing ground while ensuring that the engagement in Gau was at a small and manageable level that will be assessed by the people. Over the three years of the Mositi Vanuaso, the community-based resource management activities diffused into the other two districts because the local people throughout the island were impressed with the positive outcomes of the trial, which included the management of marine resources, management of waste, protection of 
watershed areas, rehabilitation of coastal habitats, capacity building and securing of alternative sources of livelihood. As can be seen from the list, the evolving and iterative approach encouraged the people to actively formulate and shape their resource use activities and their children's future utilising their traditional practices, available funds and advice without waiting for the national government's directive, guidance and leadership.

Unfortunately, many coastal communities are ill informed of the threats of rural development and the consequences of the commercial use of their resources, which they are offering in exchange for the money they require for their development activities. For this is reason, resource management awareness and education workshops and meetings at the levels of villages, districts and island were emphasised in these local communities where the majority of the people have never lived outside and therefore are oblivious to the rural development challenges and the options appropriate to address them.

The awareness and training covered all important issues to be shared widely amongst all the people such as the reasons why they should be managing their resources better, resource management plans, project planning and good governance practices. The process allowed the involvement of technical experts and the introduction of new ideas. Climate change science was not mentioned because it was not easy to translate the terms and concepts. Instead, the focus was on the impacts such as coastal erosion, coral bleaching and change in biodiversity that the people can address. In this way, the villagers' marine managed areas allowed the coral and biodiversity less disturbance and recovery while the management of waste, the replanting of tree, protection of water catchment and the ban on bushfires enhance the management of the protected area and help the people adapt to climate change. Later, the villagers were happy to share that their resource management activities are consistent with climate change adaptation measures they were being urged to do. It was at this point that some aspects of climate science such as the natural increase in world temperature and the maintenance of carbon sinks, was shared with the villagers.

This engagement activities allow the people to think, determine and systematically plan the rural development activities they can pursue to meet their aspirations and maintain their environmental resources. Under Lomani Gau, the three districts and 16 village chiefs and their people decided on how their resources are utilised while the social institutions offered the line of communication as well as the enforcement arrangements. Chiefly decisions are made in consultation with members of the community and are then communicated to all those relations that need to be informed.

The Lomani Gau approach emphasises the marriage of new ideas and approaches with traditional practices under contemporary arrangements. Difficulties arise because some traditional methods such as the ownership of fishing grounds and institutions such as chiefly authority are inconsistent with national laws and 
regulations and, in many cases, are waning. On the other hand, the people are more familiar with their community-based resource management arrangements but are not aware of their responsibilities under national legislation and international conventions. The hybrid system being piloted in Gau requires significant education, which include the promotion of good practices such as seasonal prohibition (tabu), and community initiatives and sustainable technologies such as composting toilets, renewable energy targeting pertinent issues that villagers now deal with.

Biological, social and economic surveys and monitoring are undertaken to follow up, reinforce and strengthen people's commitment to their resource management initiatives, which are regularly reviewed to see how the people fair with their sustainable development commitment in the challenging context they operate in. Villagers continuously choose between the immediate incomes from the unsustainable use of their resources and the uncertain and intangible long-term return from conservation activities. This is why it is important to conduct effective consultative meetings, marine awareness and regular follow up activities. It is also critical that management actions are provided the time to work, as the positive lessons from these resource conservation efforts will inspire the continuation of conservation and resource management into the future.

The partnerships in this project has boosted the iterative method and stressed compliance to prove that conservation is more beneficial for the people and environment. The commitment to make a difference has ensured that the resource management effort on Gau is allowed the time to work and incorporate the new areas of development. Gau people have recognised and appropriated the holistic interconnecting character of climate change and been able to envision and act upon the necessary responses and work. The management system now covers the whole island and allows for contemporary approaches such as ecosystem based and ridge to reef management while the partners look for cheaper arrangements that are appropriate in rural villages.

Some of the development agencies, institutions and Non-Government Organisations (NGOs) partners that have contributed to the management of the resources and the rural development initiatives in Gau include the International Ocean Institute-Pacific Islands Operational Centre (IOI-PI), the University of the South Pacific (USP), Fiji Locally Managed Marine Areas network, the French Embassy, the National Trust for Fiji, Nature Fiji Mareqeti Viti, the World Wildlife Fund for Nature (WWF), National Fish and Wildlife Foundation, Frontier Fiji, Planetary Coral Reef Foundation, Edulink, Conservation International, Global Environment Facility's (GEF) Small Grants at the United Nations Development Programme (UNDP), Japan International Cooperation Agency (JICA), Mie University and the Fiji Government. Financial and technical assistance on fisheries management, aquaculture and alternative sources of livelihood dominate the contributions from these partners who are united to improve the lives of local communities while protecting the natural heritage of Gau. 
The work on Gau has shown the importance of awareness and capacity building to ensure that the root causes of the issues are effectively addressed. In many instances, these solutions to local challenges are outside the communities and are unknown to local people. This makes awareness and capacity building critical to the sharing of new ideas with local communities.

\subsection{The Accomplishments}

Gau Island has been transformed over the last ten years since the people started focussing on the sustainable use of its natural resources. All of the new resource management activities undertaken on Gau are expressions of the care that the people are exercising in this new context, form and guise.

All of the villages are undertaking activities to address the devastation associated with climate change. In that time, over US $\$ 100,000$ has been spent on resource management activities on Gau, which has progressed from the marine resource management activities to address the threats on land. The villagers have adopted the integrated and ecosystem based approaches to formulate 16 resource management plans that address the climate change problems the villages want to fix, declare more than 16 no-take zones within the customary fishing areas, ban wild fires and reduce deforestation, promote sustainable technologies and rehabilitate coastal habitats. Some of the villages on Gau are now operating income generating ventures to buy and sell copra, kava (yaqona), artifacts, village stores, and cattle farms while others have become honorary fish wardens, research assistants and community leaders who are leading by charting the sustainable use of the island's environmental resources.

The evolving activities of Lomani Gau reflect the iterative methods used to balance the villagers' development activities and the implementation of their climate change adaptation measures. These also reflect the achievements of parts of the village resource management plans over the years and the wide variety of issues that the people can undertake to prepare for climate change. The current aim is to declare a forest reserve over the island's montane cloud forest to be the basis of ecotourism on Gau and to improve farming practices by encouraging the villagers to farm on the lowland areas that are already cleared. This initiative has been agreed to by the Gau Island Council, which in the 1990s agreed to protect the island's forests and biodiversity to conserve the habitat of the iconic Fiji Petrel. The protection of the forests is now supported by activities to reduce deforestation and establish farm access roads.

Lomani Gau is organising regular meetings and training activities to promote the appropriate land-use guidelines recommended to protect water catchments, avoid the contamination of drinking water and reduce soil erosion and loss on Gau. The importance of protecting the forest to safeguard its ecological services are explained to the people who are encouraged to protect their natural cloud mountane forests, 
protect their water catchments as well as allow for thick vegetation as buffer zones along their rivers and coastal habitats. The people are advised not to farm right up to river and waterways to minimise soil loss and erosion to the water ways and to take precautions to ensure that their use of chemicals is not posing threats to their environment and themselves. The villagers are encouraged with incentives to plant trees in their villages and surrounding degraded areas that are commonly burned while disposal of village waste through better sorting, proper disposal methods such as the use of designated rubbish pits and the care of pigs to lessen their destructive influence in the villages and surrounding areas. Composting toilets and the maintenance of healthy and clean living environment are now pursued in all the villages and supported through a yearly Most Beautiful Village in Gau Competition in which all the villages participate.

Surveys of the ecological, social and economic issues on the island have been undertaken and used to determine the development activities undertaken by Lomani Gau in each village. These surveys and methods strengthen people's commitment and are key moments of cultural translation where scientific information and people's traditional resource use practices reinforce each other. The work in Gau nicely demonstrates the global connections that climate change provides in linking near and distant places together as part of a single issue.

Lomani Gau has collaborated with the villagers to set up fish aggregation devises (FAD), or artificial structures to stimulate the aggregation of pelagic fish, in three parts of the island where the fishing is best, and three village cattle farms. The FADs support the recovery of reef based fisheries and target the pelagic stocks rather than the demersal species that are normally targeted while the cattle farms are to demonstrate the proper animal husbandry practices. Training workshops and follow up activities are organised in villages, districts and island levels to formulate and endorse activities that are consistent with a Code of Conduct for Sustainable Living on Gau Island that is being negotiated with the villagers.

Frontier Fiji, a subsidiary of the United Kingdom registered Society for Environmental Explorations, was in Gau between 2006 and 2012 conducting biological surveys of the coastal habitats and sharing their findings with villagers in Sawaieke and Navukailagi districts. The Reseach Assistants and Frontier Staff Members provided a volunteer/tourist workforce to assist the local villagers with their resource management initiatives. The group endured hardship and trying conditions to produce some of the first reports on the state of the coastal habitats and marine resources on the island. The visitors stayed for two to ten weeks while staff stayed for a year and represented the type of intrepid adventurous tourism that can be enticed to visit remote tourist destinations such as Gau.

New ideas that have been introduced to people in Gau include participatory decision making that is more inclusive and allow the involvement of youth and women in decision making; the use of the integrated resource management approach that emphasise the involvement of all stakeholders in addressing all of the issues 
that people need to deal with to adapt to climate change and the implementation of appropriate alternative sources of livelihood that the people will succeed in and benefit from. Women, youth and children are using their opportunities and are undertaking community initiatives that are consistent with Lomani Gau aims. FADs are innovative methods that are welcomed by local villagers who are catching yellow fin tuna, trevally and Spanish mackerel from these devices. In addition, the cultivation of pandanus, and the weaving and selling of Gau mats in Suva, has opened a new market for this traditional item and involved men and women who are bringing into Gau around F\$1,000 per month-money that has supported better living standards on the island.

Lomani Gau seeks and secures the funding to conduct training and follow up activities such as meeting the costs of transportation to the Gau Island Council meetings. The network supports strengthening of governance at all levels of administration on the island. It is assisting the Gau Island Council to coordinate local government activities and has set up Lomani Gau Tikina Committees to lead community work in the three districts. Over the last three years, Lomani Gau has collaborated with the village nurses and the Fiji Health Department on the island to organise "Gau's Beautiful Village" competition (Koro Vakasakiti e Gau), where the three villages judged best in addressing all the sustainable rural development issues are rewarded.

Some of the initiatives currently undertaken in Gau to appropriate climate change impacts include: reducing the deforestation associated with the customary shifting cultivation method where people farm a piece of land for around three to five years before they move to clear a new farming spot where they practice multiple cropping; minimising the indiscriminate and careless burning of secondary vegetation on coastal slopes which threatens biodiversity including the Fiji Petrel, lizards, snakes, and natural forests; protecting watersheds and drinking water sources by declaring forest reserves and reducing deforestation and farming activities in water catchment areas to assure continued water supply; minimising hillside cultivation to reduce soil loss and erosion; rehabilitating degraded coastal habitats such as coral reefs and mangrove forests by declaring marine managed areas and replanting coastal vegetation such as mangrove forests to enhance their health and integrity; and the sustainable use and management of coastal resources such as fisheries and coastal lowlands to provide the needs of future generations.

Appropriating the locally observed impacts of climate change made it easier to convince the people of the actions they need to take to adapt to climate change. This appropriation of climate change impacts means that the people use the "climate change" label to mobilise all necessary community-based sustainable development schemes that they would have wanted to do anyway, even without climate change. Between 2011 and 2013, Gau villagers have implemented a coastal vegetation rehabilitation initiative funded by the Global Environmental Facility (GEF) Small Grants and the UNDP. The villagers planted over 100,000 trees during the project 
period and were awarded the 2013 Prime Minister's Forest Conservationist of the Year award by the Ministries of Agriculture, Fisheries and Forests, which have promised training assistance, seedlings and technical advice on the reserve and heritage site that the people of Gau are currently discussing. Tree planting on the island is now used to maintain environment health by ensuring that the vegetative cover is maintained to reduce soil erosion and loss, prepare for climate change, enhance the inshore or reef-based fisheries resources by diverting some of the fishing effort elsewhere and provide an alternative source of income.

The success of this coastal rehabilitation initiative is strengthening the commitment in Gau to protect the old-growth forest and pursue alternative uses of the forested lands. There is growing interest in Gau to declare the island a heritage site where people can live full lives in harmony with nature. The Gau Island Council has endorsed moves to declare the cloud forest a reserve, partly to boost the potential for ecotourism. With the marine protected areas, cultural sites and natural and geographical features such as the shark nursery and submerged offshore reefs, Gau people should have enough attractions to entice ecotourism which can be hosted by local landowning groups. This would promote Gau as an ecotourism destination and offer new income sources to local people.

In 2013, Mie University in Japan, the Department of the Environment in Fiji, IOI-PI and USP agreed to collaborate with the local villagers on a Sustainable Development and Governance in Gau project to make resource management beneficial to local communities. Some of the activities that are being pursued include the introduction of new agricultural and fishing practices including the provision of three village pig fences where all the village households will build their individual pens inside a well fenced area, another cattle farm where the people of three neighbouring villages will raise their animals and three bakeries that the villagers can use to make bread from local food crops and provide sources of income. The establishment of the village pig farms is the first phase to the production of biogas, which can be regarded a climate change mitigation activity. The proposal was shared with all the villagers in the island who were then asked to submit their proposal to be involved, which needs to include the offer of the land where the farm is to be located, the promise to provide the posts from local surroundings and the undertaking to provide labour for the venture. Pig waste for the time being will be mixed with dried grass from the villages to produce organic manure that the farmers can use. The next phase will be to cement the fenced area and build the chamber to allow the production of the biogas.

There is also an attempt to construct farm roads and permanent farms in the lowland areas of a few of the villages. These farmlands will have the designated forested buffer zones to protect the land, rivers, forests and the coral reefs. The villagers are planting sandalwood and plantation timber trees in areas of secondary growth that are commonly burnt. A model farm is now being set up to illustrate many of the farming practices mentioned above. In addition, waste management including the use of composting toilets, biogas production chambers, renewable energy 
sources and building architecture to maximise the use of local natural materials and techniques will all be demonstrated.

At sea, a bêche-de-mer enclosure has been erected in Vione to protect and raise these animals to their optimum size where they can attract their highest process. Seaweed farming is being promoted as an alternative source of income to more villages that can enhance the recovery of inshore fisheries. Solar lights have been introduced as people search for more renewable energy sources. There is now no longer any import of expensive kerosene, shell light and diesel as the people are quickly adopting the renewable sources. A youth leader from the island will spend three months in Mie University and Okinawa in Japan to learn the type of appropriate technologies that can be implemented in Gau.

This section has shared some examples of what the people in Gau have done in response to climate change impacts they now face. With the advice from their outside partners, including the authors, the people have taken actions to show their commitment to improving their lives and adapt to threats such as climate change. We now highlight some of the challenges witnessed so far.

\subsection{The Challenges}

The challenges in Gau Island are to get the local people to commit to and articulate sustainable development in all their resources management and development activities and practices. For the majority of people in rural areas, including those on Gau, these environment-friendly requirements are regarded as impediments to people's development aspirations and their rights to benefit from the exploitation of their natural resources. With the benefit of hindsight after a decade of continuous engagement with local communities, it is now easier to justify the adoption of precautionary approach given the many instances where people rush to develop their resources only to lose them to partners who were interested in the resources and not the welfare of their local partners. Such examples and lessons have forced people to reconsider their development choices. The situation has made it critical that people conduct exhaustive consultation and awareness as they plan their development activities. After a decade of working with the people in all the villages in Gau and building their capacity, sustainable development principles seem to be much better accepted and people are beginning to relate to the interrelations amongst the elements of the ecosystem that can be impacted by their development activities.

Mobilising local action in rural villages is dependent on a number of factors that include awareness level, connectivity, capacity, conviction and funding. Of these factors, awareness, capacity building and funding cannot be addressed through the traditional systems that the villagers use. Rural communities do not have these capacities because issues such as climate change are being explained in scientific terms that are new to the people. In fact, emphasis on emissions makes climate 
change adaptation and mitigation only remotely relevant to rural villages where the only machineries used are the diesel generators, brush cutters and outboard engines. The general feeling then is that the developed countries are responsible for the problem and thus should be required to address it. These methods also ignore the many adaptive actions that people in rural areas can undertake to prepare for the future. As the work on Gau demonstrates, capacity building is important to convince the people of the part they have to play. Outside advisers have to create awareness, build capacity and provide advice on appropriate technologies for which funding has to be sought and secured. Local people live in semi subsistent societies where money is required to meet the costs of transport, experts and materials for organising community activities. This is why the Global Environment Facility and the UNDP established its Small Grants scheme. Sadly, the requirements for accessing this financial assistance many times still isolate local communities in rural areas such as Gau.

The lack of government support for community development is hindering many community driven initiatives. Government ministries should ensure that people in local communities are not responsible for enforcement and surveillance. In fact, government agencies should establish the guidelines, funds and rewards for those that succeed in attaining their community-based objectives. The people of Gau have over the last decade shown their commitment and support for resource management and are assisting the Government in meeting its commitments to sustainable development.

Technical advice from external partners on issues that are new to local communities have benefited the people. Fish aggregation devices, composting toilets, smokeless stoves and renewable energy are new technologies that are being tried in Gau to adapt to climate change. Human and pig waste is being managed to realise the monetary implications that such innovations offer. External partners are assisting with these new initiatives.

The enforcement of management decisions agreed to at local levels remains a challenge because of the erosion of traditional authority and the reliance on legislations people know little about. Traditional authority and institutions that used to uphold local decisions and banish people who do not adhere to the community's wishes in the past are still useful at the local level today but must be supported by the Government when local communities are dealing with the activities of people from outside the communities. This is the reason why the main threats to local resources management activities come from outside the communities. For this reason, locally managed marine areas are targeted by commercial fishers who regard these as prime fishing areas that they have the resources to access whenever they wish. The Fiji Fisheries Department, as the licensing authority responsible for developing and managing the fisheries resources, must address poaching from local communities where the people are least prepared to deal with these external threats. 


\subsection{The Lessons Learned and Way Forward}

Small islands such as Gau offer useful lessons on how local people are living with the impacts of climate change and are adopting resource management initiatives to improve their living standards. The villagers have declared marine managed areas, planted mangrove forests, seaweed and trees, and are now pursuing the use of renewable energy and the management of their waste to ensure that the ecological services offered by their environment will provide for them in the future. The resource management and development activities undertaken in Gau over the last decade highlight the contribution of local communities to the management of their environmental resources. The interventions have shown what the people in these communities can do to utilise their own resources, including traditional knowledge and practices, to improve their living conditions. The experience in Gau has proven that local communities can lead the drive to adapt to climate change.

The engagement of people in Gau took advantage of the local people's social units such as traditional practices and relations. Close-knit social units such as extended families, villages and districts enhance the participation of local communities and the implementation and enforcement of the people's resource management decisions. Community-based climate change adaptations are easy to organise and produce quick results but need to be maintained over the long term to allow for the desired recovery. Long term engagements are challenging as external inputs are required to maintain the focus of local people in the management of their resources. The people normally are ready to commit to resource management but are uncertain about the duration of the management period because they depend on the use of their resources. Interestingly, more and more community groups are actively managing their natural resources because the future of their children in a climate change ravaged island is at stake.

Training and community workshops are required to engage, mobilise and maintain local initiatives. Local engagement processes require that capacities are built to enhance people's understanding of climate change issues and their personal role in addressing these. Capacity building processes are necessary as much of the climate change science is new to local communities, which need to be informed on how they can use their arrangements to adapt to climate change issues. Innovative and regular follow-up activities are necessary to introduce and maintain new adaptive techniques that can be assimilated by local communities and also to check on progress made.

The search for alternative sources of income has been significant in Gau because of the need to relate to climate change adaptation while providing much needed income in rural areas, where people are paying higher prices for goods and services. Alternative sources of livelihood are chosen carefully in accordance with people's resources, skills and needs and their natural resources endowment. For the Lomani 
Gau initiative, the protection of food sources is the foundation for climate change adaptation, resource management and poverty alleviation.

Women and youth are specifically targeted in Gau because they constitute the largest community groups who have not previously been given leadership roles. The village store in Vanuaso has been operating for the last decade since it was established under Mositi Vanuaso and is run by the village youth. In Malawai, the women have been selling mats in Suva for the last decade and have created an urban market for this traditional skill, which has strengthened this traditional art and provides a welcome source of income. In Lamiti, the youth is buying kava (yaqona) from the members so that they are spared the time-consuming marketing trip to Suva where some of the young farmers have lost all of their hard-earned income. In Malawai, Lekanai and Vadravadra, the youth groups are looking after their community cattle farms. Lomani Gau is now well represented in the Gau Island Council where all the 16 Turaga ni Koro (village headman) who are using the network to better coordinate the climate change adaptation work in their villages. This empowerment has improved community-based resource management in the villages.

Poaching from community-based resource management areas remains a stumbling block to resource management at the local level and is a source of social and cultural pressure and conflicts. The problem is tied to the commercial trade of food sources by increasing number of villagers that want to improve their income. Fishing is the most attractive way to make money in coastal communities but overfishing eventually leads to food insecurity for the local people. Moreover, the lack of funds and income generating activities in these rural communities force the people to sell their environment resources at any cost when they have the chance. These issues make resource management both critical and difficult because the effectiveness of these activities will always be skewed.

Villagers are pragmatists; they will adopt new ideas and practices if they are convinced that these will benefit them. The villagers in Gau are convinced that a healthy environment is the best way of appropriating climate change. They are demonstrating great resilience and adaptability in accommodating climate change conditions. However, the villagers require advice, human capacity, and finance to better articulate sustainable development in their context. Given what has been achieved in Gau over the last decade with limited financial resources, it will be interesting to imagine the outcome at the national, regional and global levels if there is a concerted effort to engage and support local community groups in sustainable development and climate change adaptation.

The future looks bright if the small steps that have been taken in the rural communities in Gau are an indication of what can be accomplished if the same approach is adopted in other areas. Once the momentum is attained, social transformation can be widespread. This is why local case studies need to be promoted widely to share the lessons and changes globally. In Gau Island, care of 
their environment is now the basis of climate change adaptation and sustainable development activities that the people hope will enable them to move away from their present environmentally exploitative positions towards one that protects their natural environment while supporting their development activities. 